Special issue of the 3rd International Conference on Computational and Experimental Science and Engineering (ICCESEN 2016)

\title{
Using Photovoltaic Panels for Irrigation
}

\author{
A. SEnPInAR* \\ College of Technical Sciences, Department of Electronics Technology, Firat University 23100, Elazig, Turkey
}

\begin{abstract}
Renewable energy sources are getting more and more popular due to the increasing world population and decreasing conventional sources. In recent years, climate change and global warming have also increased the amount of water needed for irrigation. Renewable energy sources may therefore be used to develop photovoltaic pumping systems. Using photovoltaic arrays to drive water pumping units for irrigation in remote areas and desert regions is an economical solution. The sizing of photovoltaic pumping systems is important in order to optimize the power peak of photovoltaic array and for the choice of motor, pump and inverter (when needed). A photovoltaic pumping system consists of at least six basic components: a photovoltaic array, a dc pump motor, a battery-charge regulator, a water tank, humidity sensors and an electronic control unit. The usage of such system is in a natural relationship between the availability of solar radiation and water requirement. In this study, the designed system is an electronically controlled system, based on humidity sensors. The water requirement increases with increasing solar radiation. Hence, the dc motor is operated by means of an electronic control unit. When humidity in the soil reaches a certain value, the dc motor is stopped. The operation of the control unit relies on the data received from humidity sensors. The designed system was implemented and the obtained results were satisfactory.
\end{abstract}

DOI: 10.12693/APhysPolA.132.625

PACS/topics: 84.60.Jt

\section{Introduction}

Global atmospheric conditions cause greenhouse gases, which in turn lead to climate change and global warming. The environment is drying up and the need for water is rising. In Turkey, the majority of the available water is used in agricultural areas. In order to stop water waste, the existing water sources must be used consciously.

Solar energy has the advantages of being abundant, continuous, renewable, environmentally-friendly and clean. Photovoltaic (PV) solar batteries are used to generate electricity from the sunlight. The amount of radiation from the Sun is an important parameter for the design and calibration of PV solar battery systems. These systems are generally used to meet the electricity needs of remote areas.

The use of PV powered water pumping systems for agricultural irrigation is one of the applications of solar energy. In order to benefit from this kind of energy, a special system is needed to pump the water. The characteristics of the pumping system, i.e. the solar battery, local climate data and soil, must be analyzed [1].

Various small size systems involving solar batteries exist. These systems have undergone fast and easy data measurement and modeling procedures [2]. In some studies involving irrigation, various analyses have been made for modelling, monitoring systems and their performance analyses $[3,4]$. An example of small scale irrigation is the solar powered system in the renewable energy park of the EIE [5]. Solar panels have a wide array of use in buildings, water pumping, roads, car parks, grid dependent and independent PV systems, PV stations, etc. [6, 7].

*e-mail: asenpinar@gmail.com
Thus, a number of works on this subject were performed $[8-11]$.

The present study aims to develop an electronically controlled automatic irrigation system operated by humidity sensors, placed in the earth. The system was tested in laboratory conditions and favorable outcomes were obtained.

\section{The PV powered system design}

With the increasing population, the demand for energy is also on the rise. In the sizing of PV pumping systems, it is important to optimize the power of the PV panel, motor, pump and if necessary the inverter choice. A PV pumping system has six basic parts: a PV panel, a dc pump motor, battery and charge unit, water tank, humidity sensors and electronic control unit. The operation of the system depends on the relationship between radiation and the need for water. If radiation increases, so does the need for water. Figure 1 shows the block diagram of the designed system, while Fig. 2a shows the general overview of the system during the experiment. Figure $2 b$, on the other hand, shows the current and voltage values in the PV panel during operation.

Certain parameters must be known for the sizing of the elements of a water pumping system: daily amount of water, the height to which the water will be pumped and the appropriate water amount. Multiplying the pumping height with the amount of water to be pumped yields the power of pumping, based on time and other variables, and this power determines the size of the pump motor.

This is followed by calculation of the size of the solar panel to meet the required demand of power. In the MKS unit system, motor power is calculated in HP as follows $[12,13]$ : 


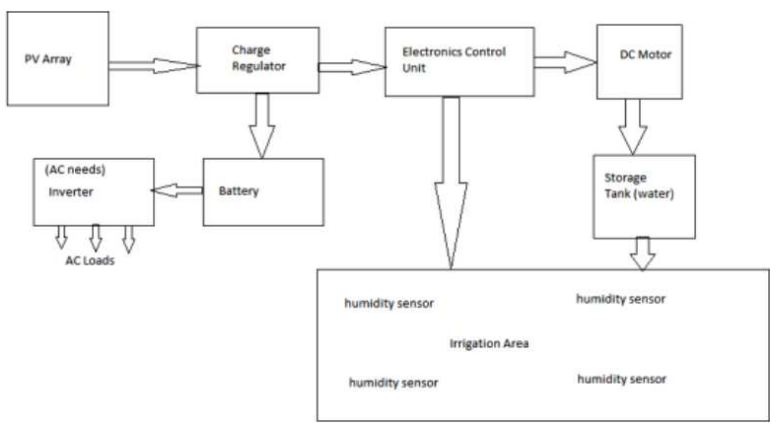

Fig. 1. The block diagram of the designed system.
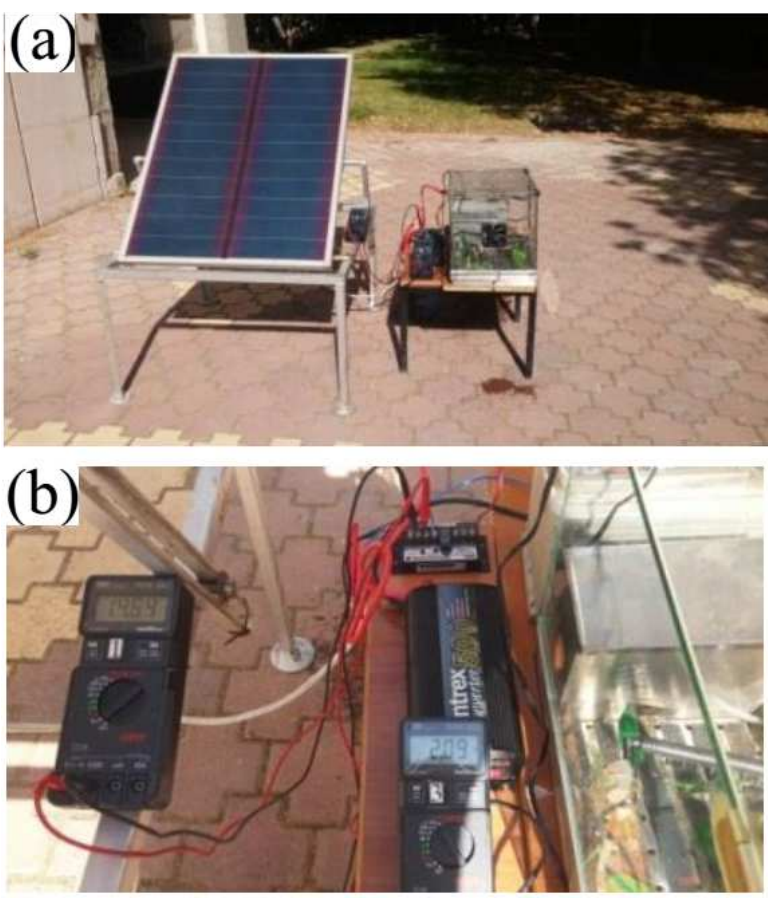

Fig. 2. The general overview of the system.

$$
\mathrm{HP}=\left(3.658 \times 10^{-6}\right) \frac{(\mathrm{LPD} \times h)}{(\mathrm{PT} \times \mathrm{PTF} \times \eta)},
$$

where, LPD is the daily amount of water to be pumped, in liters and $h$ is the effective pumping height, in meters. Effective height is the sum of the distance from the upper point of the water source to the delivery point, including pipe-friction losses (limited to approximately $5 \%$ of total effective height). Piping friction loss is determined by the type and diameter of the pipe used, just as voltage drop is determined by the size and material of the wire used.

Pumping time will be the same as the duration of hours of maximum sunning. The multiplication of PT with PTF represents effective pumping time at maximum sunning. When PV systems are used, the daily water pumping volume increases by $20 \%$, thus making the PTF value 1.2. If PV systems are not used, the PTF value is 1 . A simple example of calculation of a PV pumping system is given below.

\subsection{An example: calculation of $P V$ pumping system}

Suppose a volume of 3430 liters per day is required for irrigation purposes. The reservoir from which the water is to be pumped, is located 300 feet underground, and the case peak sun hours during the irrigation period are 6 hours. The problem is to calculate the needed components for a PV water pumping system to supply this amount of water.

First, as shown in Eq. (1), the pump power can be calculated, assuming $\mathrm{PT}=6, \mathrm{PTF}=1$ and $25 \%$ pump efficiency. If the $5 \%$ piping loss is taken into account, the new value of effective height becomes $1.05 \times 300=315 \mathrm{ft}$. By using these values in Eq. (1), the required motor power is $2.61 \mathrm{HP}$. The designer must now choose from available sizes, meaning either a $2.5 \mathrm{HP}$ or a $3 \mathrm{HP}$ pump. The pump motor will only be delivering maximum HP for a maximum of a few hours near solar noon. Prior to and after this period, the pump will receive less power from the PV array and will thus operate at a lower power. The PV array size can be determined by assuming the same current at full Sun, as the pump requires, taking into account a $10 \% \mathrm{PV}$ array degradation factor. Assuming a $10 \%$ degradation factor, the power of PV array may be calculated as follows:

$$
2.63 \mathrm{HP} \times 746(\mathrm{~W} / \mathrm{HP}) \times(1.1)=2158.17 \mathrm{~W} .
$$

In order to find the motor voltage, it is useful to calculate the motor current required at different voltages. Depending on the distance from array to motor, this could result in the use of large wire size to prevent excessive voltage drop. A higher voltage is thus preferred. For example, assuming a $2160 \mathrm{~W}$ power level, a $12 \mathrm{~V}$ motor would draw 2160/12 = 180 amperes. At $24 \mathrm{~V}$, the motor current will be $90 \mathrm{~A}$. If $12 \mathrm{~V}, 5 \mathrm{~A} \mathrm{PV}$ arrays are used, the system needs 36 PV arrays, connected in parallel. Similarly, if $24 \mathrm{~V}$ arrays are used, they could be connected as 18 parallel sets of 2 in series.

\subsection{The experimental application}

A humidity sensor is used to measure the amount of humidity in soil. It is used by inserting the probe into the environment in which the measurement is to be made. Owing to the resistance caused by the soil or the liquid into which the probes are inserted, a voltage difference occurs between the probe ends. The amount of humidity is decided based on the size of this difference. As the humidity of soil increases, so does its conductivity. With a potentiometer on the electronic card, the sensitivity of soil humidity level may be adjusted (Fig. 3).

The PV powered water pumping system designed here is a small automatic watering system, based on humidity sensors. The system is aimed for use in orchards and small or large scale agricultural fields. The voltage of the PV panel rises in proportion to solar radiation. This voltage charges the battery via the charge regulator. If desired, night time power needs may be met by the battery. The dc load in the system may be operated directly over the battery. If there is an ac load, an inverter needs to be added to the system. During the day, 


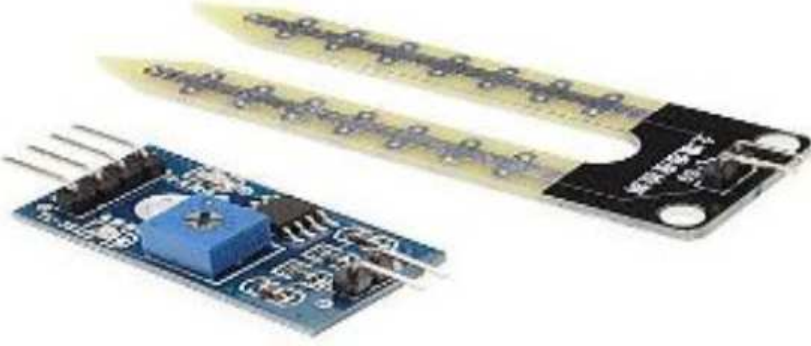

Fig. 3. Humidity sensor and electronic card.

the pump keeps irrigating and also maintains storage in the water tank. If data from the humidity sensors reveal increased dryness in the soil, the dc motor starts operating under the control of the electronic control unit and irrigation starts (Fig. 4).
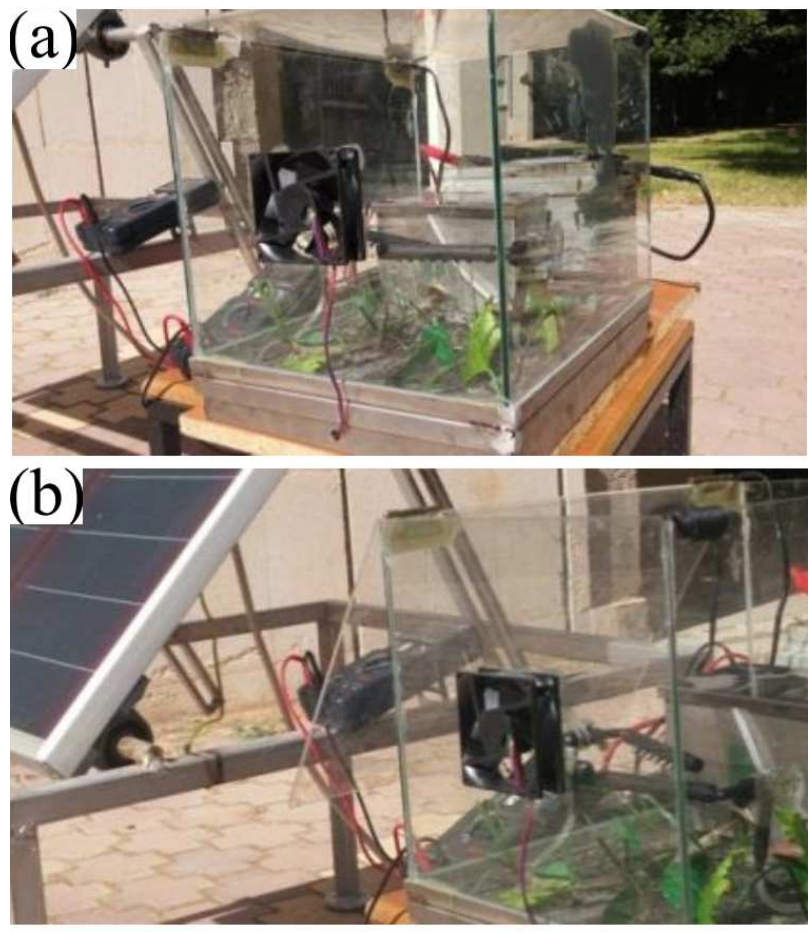

Fig. 4. Changing in pump motor (start-stop).

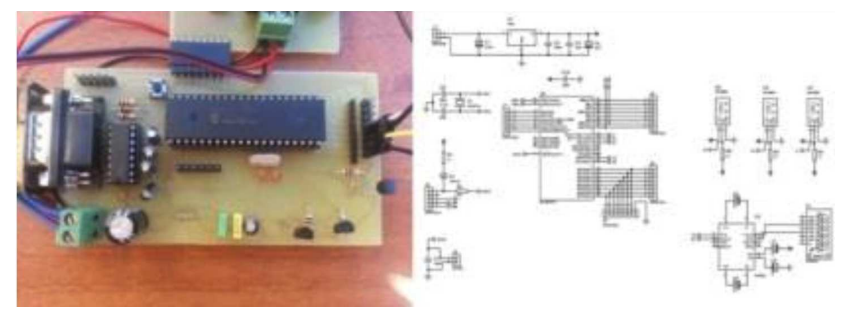

Fig. 5. The electronic control unit.

Water collected in the tank is used when necessary, for example in overcast weather or at night. Soil humidity sensors have been placed in different parts of the system. When the humidity level of the soil reaches a pre-specified value during irrigation, a signal is sent to the electronic control unit by the sensors. The electronic control card then stops the motor (Fig. 5). After a while, similar steps are repeated based on the dryness or humidity levels of the soil.

\section{Results and discussion}

The designed system yielded successful results in experimental conditions. Within the system, a $12 \mathrm{~V}$ dc pump motor was preferred. As a result, the pump motor is fed by the battery. In the designed system, the humidity sensors buried in the earth, control the pump motor. In this way, not only the excessive water consumption is prevented, but also time and human power is saved. Data from humidity sensors are processed by the electronic card and then used to either start or stop the automatic irrigation system, based on the desired humidity level.

The power needed by the designed automatic water pumping system is supplied by the PV panel in the system. The power of the electronic control unit in the system is approximately $5-10$ Watts. The power of the dc pump is approximately $10-15 \mathrm{~W}$. The total need is approximately 20-25 Watt, thus meaning that a $30 \mathrm{~W}$ PV panel may meet the needs of the system. During the experiment, a $42 \mathrm{~W} \mathrm{PV}$ panel, available in the laboratory, was used. The size of the PV irrigation system may change according to the size of the agricultural land to be irrigated. The PV pumping system is an advantageous, economic and sustainable system.

\section{Conclusions}

The aim of this study was to present the advantages of an automatic agricultural irrigation system, operated by electrical energy obtained from the Sun. The system may benefit the country's economy if it can be extended for use in the vast irrigated lands of the east and southeast. With technological advances, the system may give farmers, worker, water, time and efficiency advantages. If the system is used for landscaping in city parks and green spaces, it may bring other advantages. With the system, water waste and the need for human power may be decreased. The system is economical and easy to use. If future studies will add to it smart mobile device applications and remote controlled RF systems, it would be also possible to monitor the system online.

\section{References}

[1] Z. Glasnovic, J. Margeta, Solar Energy 81, 904 (2007).

[2] M. Jafar, Renew. Energ. 19, 85 (2000).

[3] R. Illanes, A. De Francisco, J.L. Torres, M. De Blas, J. Appelbaum, Prog. Photovoltaics 11, 453 (2003).

[4] J.M. Green, M. Wilson, W. Cawood, Dev. Southern Afr. 18, 19 (2001). 
[5] General Directorate of Electrical Power Resources Survey and Development Administration (EIE), www.eie.gov.tr/turkce/YEK/gunes/eiegunes.html, Turkey 2016.

[6] Y. Kuwano, Renew. Energ. 15, 535 (1998).

[7] M. Kolhe, J.C. Joshi, D.P. Kothari, IEEE T. Energy Conver. 19, 613 (2004).

[8] N.C. Bezir, I. Akkurt, N. Ozek, Energy Sources A 32, 512 (2010).

[9] Z. Er, Acta Phys. Pol. A 128, B-300 (2015).
[10] N.C. Bezir, I. Akkurt, N. Ozek, Energy Source A 32, 995 (2010).

[11] Z. Er, Acta Phys. Pol. A 130, 72 (2016).

[12] R. Messenger, J. Ventre, Photovoltaic Systems Engineering, Crc Press, Florida 2000.

[13] W.A. Beckman, J.A. Duffie, Solar Engineering of Thermal Processes, 2nd ed., John Wiley and Sons, Canada 1991. 